\title{
Usando Mapas Conceituais para uma Aprendizagem Significativa de Geometria
}

Charline da Silva Andreola ${ }^{\star}$, João Carlos Krause ${ }^{\star \star}$, Rozelaine Contri ${ }^{\star \star \star}$

\section{Resumo}

O contexto educacional atual exige uma constante reflexão sobre as metodologias utilizadas em sala de aula. A busca por alternativas capazes de motivar os estudantes, facilitar a aprendizagem e torná-los sujeitos ativos na busca pelo conhecimento é essencial. Diante disso, este trabalho apresenta o resultado de uma pesquisa realizada com alunos do nono ano do ensino fundamental e da terceira série do ensino médio de uma escola pública da rede estadual de ensino do Rio Grande do Sul. O objetivo foi analisar se a construção de mapas conceituais utilizando o software CmapTools pode auxiliar no processo de ensino e aprendizagem de geometria. As observações aconteceram durante as aulas de Matemática e a metodologia utilizada baseou-se na análise dos mapas elaborados pelos alunos. Também foram analisados resultados de um pré e um pós teste com questões envolvendo conteúdos de geometria. Ficou evidente que a elaboração dos mapas conceituais possibilita que aluno e professor percebam as dificuldades existentes no processo de ensino e aprendizagem. Também pode-se afirmar que o mapeamento conceitual aliado à tecnologia pode ser uma estratégia capaz de oferecer perspectivas positivas para a prática educativa e possibilitar a aprendizagem significativa dos conteúdos de geometria. Além disso, motivou a participação dos estudantes na dinâmica de trabalho em sala de aula, durante a construção e apresentação dos mapas conceituais.

Palavras-chave: Aprendizagem significativa. Geometria. Mapas conceituais. Software CmapTools.

- Mestra em Ensino Científico e Tecnológico- URI Santo Ângelo. Professora da rede pública estadual do Rio Grande do Sul e da Escola de Educação Básica da URI- Santo Ângelo, Santo Ângelo, RS, Brasil. Avenida Universidade das Missões 505, apartamento 302, Bairro Universitário, Santo Ângelo, RS, Brasil. E-mail: charlineandreola@gmail.com.

** Doutor em Ciências - UFRGS. Coordenador do Programa de Pós-Graduação em Ensino Cientifico e Tecnolígico da Universide Regionalk Integrada do Alto Uruguai e Missões (PGEnCT - URI), Santo Ângelo, RS, Brasi. Avenida Venâncio Aires, 3692. Centro Norte, Santo Ângelo, RS, Brasil. E-mail: krause@santoangelo.uri.br.

*** Doutora em Engenharia de Produção - UFSC. Docente permanente do Programa de Pós-Graduação em Ensino Cientifico e Tecnolígico da Universide Regionalk Integrada do Alto Uruguai e Missões (PGEnCT - URI), Santo Ângelo, RS, Brasi. Rua Adão Felipe Pippi , 90. Bairro Esperança, Santo Ângelo, RS, Brasil. E-mail: rozelaine@ santoangelo.uri.br. 


\section{Introdução}

No presente trabalho, o objetivo da pesquisa foi verificar se o mapeamento conceitual pode contribuir para uma aprendizagem significativa de geometria por meio da construção dos mapas conceituais, sendo que buscou-se consolidar mais especificamente os mapas conceituais como uma ferramenta facilitadora do processo de aprendizagem.

Partimos da premissa, que a Matemática desempenha um importante papel no contexto educacional e social, e constantemente percebe-se as dificuldades encontradas na aprendizagem de conteúdos desta disciplina. A necessidade constante de conteúdos anteriores (pré-requisitos), para estabelecer relações para o entendimento de um novo conteúdo é algo corriqueiro no ensino de Matemática, incluindo neste contexto conteúdos de geometria.

Assim, buscou-se uma maneira de contribuir e servir como uma ponte capaz de interligar diferentes conceitos e conduzi-los de uma aprendizagem considerada mecânica para uma aprendizagem significativa.

Para realização deste trabalho, escolheu-se mapas conceituais, pois na prática docente, foi observado que os alunos demonstravam interesse quando a professora construía esquemas na revisão de conteúdos e que alguns desses alunos, elaboravam o seu "esquema" para facilitar a realização das questões propostas, principalmente as relacionadas com geometria, tanto em aula como nas avaliações.

A preocupação em especial com a geometria deve-se a sua importância em situações do cotidiano, facilitando assim a sua contextualização, mas também por ser uma ponte que liga diferentes conteúdos e facilita a aprendizagem e fixação de conteúdos algébricos.

Nas próximas seções descreve-se alguns aspectos teóricos relacionados ao tema de pesquisa. Na primeira seção aborda-se o ensino de geometria, analisando a sua importância e as dificuldades de aprendizagem. A segunda, versa sobre alguns aspectos relevantes acerca da teoria da aprendizagem significativa, base para a metodologia dos mapas conceituais. Na terceira, o mapeamento conceitual é apresentado como facilitador da aprendizagem significativa e organizador do conhecimento. $\mathrm{Na}$ última, são detalhadas a parte prática da pesquisa, análise de mapas conceituais e a coleta dos dados, culminando com a discussão dos resultados mais relevantes. 


\section{Ensino de Geometria}

Para Nunes (2010) no Brasil, as mudanças sociais que ocorreram durante o século XX fizeram com que ocorressem mudanças no ensino da Matemática. Um exemplo disso é que, dentro de uma sociedade agrária e pecuária poucas pessoas precisavam saber Matemática e, quando surgiu a sociedade industrial, aumentou a necessidade de dominar alguns conhecimentos matemáticos voltados aos processos de industrialização, como aritmética, geometria, álgebra e trigonometria, essencialmente para a formação de engenheiros e topógrafos, empregados em minas, abertura de estradas, construções de portos, canais, pontes, etc. (VALENTE, 1999). Para Pavanello (1993) no início do século XX o ensino de Matemática na escola primária era essencialmente utilitário, ou seja, ligado à prática diária e às atividades comerciais.

No início da década de sessenta, o ensino de Matemática no Brasil passou por modificações, sofrendo influências do Movimento da Matemática Moderna, que pretendia aproximar a Matemática trabalhada na escola básica com a Matemática produzida pelos pesquisadores na área (PAVANELLO, 1993).

A partir daí o ensino da Matemática baseia-se no estudo das estruturas algébricas, na teoria dos conjuntos e a geometria perde seu caráter intuitivo e pauta-se na demonstração e no formalismo (PAVANELLO, 1993). Durante o Movimento da Matemática Moderna a geometria foi praticamente excluída dos currículos escolares e também de cursos de formação de professores. A matemática moderna sofreu muitas críticas e, após a constatação de que o ensino de matemática moderna tinha fracassado e a aprendizagem estudantil não estava atendendo às expectativas, inicia-se um novo modelo renovador. Essa nova fase mostra lances do que hoje é considerado Educação Matemática.

Segundo Neves (2008) quando nos referimos à geometria, falamos do espaço que nos cerca, bem como dos objetos presentes em todos os contextos. Da mesma forma Lorenzato (1995) diz que sem estudar geometria as pessoas não desenvolvem o pensar geométrico ou o raciocínio visual.

Apesar da sua importância no cenário educacional, percebe-se que até pouco tempo existia uma ausência de conteúdos geométricos no currículo escolar, o que reflete na falta de domínio destes conhecimentos em alguns estudantes concluintes do ensino médio. Assim, tentando entender os reais problemas enfrentados por pro- 
fessores nas escolas no ensino de geometria alguns estudiosos como Pavanello (1989), Lorenzato (1995), Almouloud (2004), dentre outros, tentaram buscar respostas para justificar este quadro. Além destes trabalhos, mais recentemente outros autores também se dedicaram a pesquisas relacionadas principalmente a estratégias para o ensino de geometria, como Rodrigues e kaiber (2019) e Olgin e Groenwald (2020).

Segundo as diretrizes curriculares da disciplina de Matemática, baseadas nos PCN (1998) os conteúdos matemáticos se dividem em quatro grandes eixos temáticos, sendo um destes "Geometria e medidas", eixo descrito como: tem caráter prático e utilitário. E neste sentido, a Base Nacional Comum Curricular - BNCC (BRASIL, 2018), refere-se para a importância de conceitos de geometria fazerem parte do currículo de Matemática, tendo em vista que o pensamento geométrico propicia ao estudante uma melhor compreensão do mundo ao seu redor.

A geometria é mais abordada no tópico espaço e forma, porém nota-se que o seu ensino está cada vez mais excluído das aulas de Matemática como afirma Lorenzato (1995) e Lobato e Andrade (2019).

Segundo Pavanello (1993) o abandono do ensino da geometria na sala de aula é atribuído ao contexto histórico-político do problema, e explica que, apesar deste abandono ser geral, ele se acentua no ensino público a partir de 1971, quando a lei 5692/71 possibilitou que cada professor elaborasse o seu programa de conteúdos de acordo com a necessidade dos alunos.

$\mathrm{Na}$ tentativa de entender o porquê das dificuldades no ensino da geometria é preciso buscar informações de quem está diariamente em sala de aula, ou seja, com os professores. Almouloud (2004) foi buscar nestes profissionais as origens das dificuldades encontradas no processo de ensino e aprendizagem da geometria. Para o autor, um dos fatores que gera problemas é o próprio sistema educativo, que deixa para cada escola definir os conteúdos que julga importante.

Logo, constata-se que, apesar da geometria ser uma área importante da Matemática com infinitas aplicabilidades, o seu ensino vem enfrentando problemas a décadas e isso se reflete nos conhecimentos adquiridos (ou não) pelos estudantes. Assim, além de compreender os motivos que tem levado as dificuldades do ensino de geometria é preciso buscar soluções capazes de auxiliar professores preocupados com a aprendizagem significativa dos seus alunos. 


\section{Aprendizagem Significativa}

Para que o processo de aprendizagem ocorra de maneira satisfatória, é preciso que o aluno tenha interesse em aprender e para isso um dos desafios do professor na atualidade é buscar novas metodologias que motivem os estudantes, mas, ao mesmo tempo, que possibilitem o aprendizado e faça com que sejam feitas as relações importantes entre os conceitos, para que um determinado assunto seja aprendido e, acima de tudo, adquira algum significado.

É muito comum no planejamento das aulas se buscar a base ou os conceitos iniciais de determinados assuntos, a fim de que os estudantes percebam que não se trata de algo novo, mas uma sequência do que já foi estudado e supostamente entendido. Conseguir fazer essa relação entre conceitos é importante para tornar a aprendizagem significativa, que segundo Ausubel (2003), seria ampliar e reconfigurar ideias pré-existentes na estrutura mental e com isso ser capaz de relacionar e acessar novos conceitos.

Para Moreira (2012) a aprendizagem significativa ocorre quando as ideias interagem de maneira substantiva e não-arbitrária com aquilo que o aprendiz já sabe. Moreira salienta que substantiva quer dizer não-literal e não-arbitrária significa que a interação não é com qualquer ideia prévia, mas com algum conhecimento especificamente relevante já existente na estrutura cognitiva do sujeito.

O conhecimento relevante já existente pode ser um símbolo significativo, um conceito, uma proposição, um modelo mental ou uma imagem que David Ausubel (2003) chamava de subsunçor ou ideia-âncora. Moreira (2011) afirma que quando um subsunçor serve de ideia âncora para um novo conhecimento, ele próprio se modifica adquirindo novos significados.

Por outro lado, pode-se perguntar: se a aprendizagem significativa necessita da existência de conceitos prévios que sirvam de base para o novo conhecimento, se estes não existirem (subsunçores) haverá chances de que ocorra aprendizagem? Ausubel (2003) também se preocupou com esta questão e salienta que é aí que entram os organizadores prévios que servirão de "ancoradouro provisório" para a nova aprendizagem e levarão ao desenvolvimento de conceitos, ideias e proposições relevantes.

Ainda segundo Ausubel (2003), existe a estrutura cognitiva ${ }^{1}$, considerada como uma estrutura de subsunçores hierarquicamente organizados e caracterizada por 
processos facilitadores dessa aprendizagem. Ausubel denomina esses processos como: diferenciação progressiva e reconciliação integradora.

Dentro da diferenciação progressiva o que é mais relevante deve ser trabalhado desde o início e em seguida aplicado em exemplos, exercícios e situações problemas. Por outro lado, a reconciliação integradora possibilitará que o estudante consiga relacionar conceitos e proposições, verificando diferenças e semelhanças.

Infelizmente não é possível mudar rapidamente a maneira de aprender. Para que isso ocorra é importante que existam subsunçores adequados, uma predisposição do aluno para aprender, materiais potencialmente significativos e a mediação do professor, cujo papel principal é desafiar os conceitos já aprendidos, para que eles se reconstruam e assim sejam mais inclusivos em relação a novos conceitos. Se não houver todos esses fatores, certamente predominará a aprendizagem mecânica.

Assim, o professor tem um papel importante na promoção de uma aprendizagem significativa. Para isso o docente precisa avaliar-se constantemente, já que aprendeu e muitas vezes faz com que os estudantes aprendam de maneira mecânica. Para isso é necessário desconstruir algumas posturas presentes na prática docente. Segundo Santos (2013) o professor deve: 1) Parar de dar aulas: pois quando o faz passa a impressão de que o mundo está pronto e acabado; 2) Parar de dar respostas: aprender é fruto do esforço; 3) Procurar novas formas de desafiar os alunos; 4) Buscar a aprendizagem profunda, que ocorre quando a intenção dos alunos é entender o significado do que estudam; 5) Parar de dar tantas instruções: isso apenas favorece a dependência dos alunos e não a sua autonomia; 6) Elevar a autoestima do aluno: é possível fazer isso, desde que o professor comece a partir do que o aluno já sabe, elevar a sua autonomia e 7) Promover a interação entre os alunos: o docente deve estimular a troca de ideias e opiniões, isso estimula a ampliação de conhecimentos e a testagem de hipóteses pessoais.

Além de todas estas variáveis importantes que devem ser observadas para a aprendizagem significativa, alguns instrumentos podem contribuir na consolidação da aprendizagem significativa. Moreira (2011) afirma que um instrumento associado a este tipo de aprendizagem é o mapeamento conceitual.

Segundo Novak e Cañas (2010), a ideia fundamental da psicologia de Ausubel é que a aprendizagem se dá por meio da assimilação de novos conceitos e proposições dentro de conceitos preexistentes e sistemas proposicionais já possuídos pelo aprendiz. 
Neste sentido, saber relacionar conceitos é fundamental para a aprendizagem, de modo que quando o aprendiz tem pela frente um novo corpo de informações e consegue fazer conexões entre este e o seu conhecimento prévio, ele estará construindo significados para esta informação (TAVARES, 2007).

\section{Mapas Conceituais}

Estudos referentes à utilização de mapas conceituais no contexto educacional foram desenvolvidos por Joseph Novak no ano de 1972. O estudo de Novak desenvolveu-se dentro de um programa de pesquisa da Universidade de Cornell nos Estados Unidos, no qual buscou acompanhar e entender as mudanças na maneira como as crianças compreendiam a ciência (NOVAK; CAÑAS, 2010).

Para Novak e Cañas (2010) os mapas conceituais são ferramentas para a organização e representação do conhecimento. Eles incluem conceitos e relações entre conceitos, que são indicadas por linhas que os interligam. As palavras ou frases de ligação, especificam os relacionamentos entre os conceitos.

Toda a pesquisa de Novak (NOVAK; CAÑAS, 2010) fundamentou-se segundo a Teoria da Aprendizagem Significativa de David Ausubel, mas, é importante salientar que Ausubel nunca falou em mapas conceituais, seus estudos eram sobre a aprendizagem significativa, ou seja, quando há uma interação entre o novo conhecimento adquirido e aquele conhecimento que já existe.

O mapeamento conceitual é uma técnica bastante flexível, pode ser utilizada em diferentes situações, em todas as disciplinas e com finalidades diversas, inclusive na formação de professores (ALMEIDA et al., 2020). Dentre as aplicações, os mapas conceituais podem servir como instrumento de análise de currículo, técnica didática, recurso de aprendizagem ou até mesmo como um meio de avaliação, sendo que Moreira (2011) descreve cada uma de suas finalidades.

Como técnica didática, o mapeamento conceitual pode ser feito durante uma aula, uma unidade ou em um curso inteiro. Representam estruturas concisas do que está sendo ensinado/aprendido e, dessa forma facilita a aprendizagem. Porém, é importante observar que a utilização de mapas conceituais pelo professor como auxiliar no processo de aprendizagem só deve ser incluída em sala de aula quando os alunos já estiverem familiarizados com o assunto. 
Obviamente, o trabalho com o mapeamento conceitual exige conhecimento do assunto e a disposição para aprender. Também é necessário que o professor realize alguns passos antes de sua utilização em sala de aula, a fim de obter resultados satisfatórios. Abreu (2011) sugere que o professor: analise com antecedência o tema que deseja abordar, definir os objetivos almejados, fazer a apresentação dos tópicos, distribuí-los em uma sequência hierarquizada e fazer uso das interligações necessárias. É importante também dar conhecimento ao aluno daquilo que se espera quando for o momento de construir o seu próprio mapa, demonstrando o seu conhecimento sobre determinado assunto em momentos de aprendizagem.

De um modo geral, para a construção de um mapa conceitual, o tema principal é registrado no topo por meio de um conceito e logo abaixo são organizados os demais conceitos que tem alguma relação com o assunto principal. Os conceitos sempre são escritos em algum tipo de figura, geralmente retângulos ou elipses e estes estarão unidos por meio de uma seta, que tem a função de estabelecer a relação entre os elementos conceituais.

Não existe uma única maneira de traçar um mapa conceitual. À medida que muda a relação que se atribui entre os conceitos, ou à medida que se aprende algo novo, o mapa também muda.

Na fase final, é importante compartilhar os mapas construídos com os colegas e examinar os deles, questionando a relação entre os conceitos (MOREIRA, 2011). O mapa conceitual é um bom instrumento para compartilhar, trocar e "negociar" significados. Da mesma forma é imprescindível que ao final seja feita a avaliação dos mesmos e neste momento o professor deve questionar a não inclusão de determinados conceitos, a fim de diagnosticar o nível de compreensão e as necessidades do aluno.

$\mathrm{Na}$ avaliação da aprendizagem, o professor pode ter uma visão geral da forma como os conceitos estão organizados pelo aprendiz. É uma avaliação que busca informações sobre os significados e relações significativas entre os conceitos-chave do tema de ensino sob o ponto de vista do aluno, podendo dessa forma intervir diretamente onde houver uma "lacuna" na aprendizagem.

Segundo Tavares (2007), existe uma grande variedade de tipos de mapas disponíveis, imaginados e construídos pelas mais diversas razões, todos tendo vantagens e desvantagens para determinados propósitos. Alguns são preferidos pela facilidade de elaboração ou pela clareza, pela ênfase no produto que descreve, ou pela hierarquia conceitual que apresenta. 
Entre alguns softwares que possibilitam a construção e o compartilhamento dos mapas conceituais (Lucidchart ${ }^{2}$, Creately ${ }^{3}$, GitMind ${ }^{4}$ e Bubbl.us ${ }^{5}$ entre outros) o mais sugerido nas pesquisas realizadas é o $\mathrm{CmapTools}^{6}$, desenvolvido pelo grupo de Novak.

\section{Software Cmaptools}

Sabe-se que para elaborar um mapa conceitual pode ser utilizado apenas lápis e papel, porém, na sociedade em transformação e altamente tecnológica, é importante que o professor procure incluir as TIC's na sala de aula. Para Serafim e Sousa (2011) é essencial que o professor se aproprie das tecnologias digitais da informação e da comunicação, para que estes possam ser sistematizados em sua prática pedagógica.

Após conhecer algumas das ferramentas para elaborar mapas conceituais, optou-se pelo software CmapTools ${ }^{6}$, de fácil utilização e também por estar disponibilizada gratuitamente, na internet, para fins de pesquisa e uso acadêmico. Outro fator que influenciou na escolha da ferramenta é que, além de dedicar-se exclusivamente à construção de mapas conceituais, ele vem sendo implementado pelo IHMC (Institute for Human and Machine Cognition) e foi desenvolvido por uma equipe de pesquisadores ligados a Novak (CANÃS, 2003), um dos idealizadores do trabalho com os mapas conceituais, por isso acredita-se ter a credibilidade necessária para a sua utilização neste trabalho.

\section{Metodologia e Resultados Da Pesquisa}

O estudo foi desenvolvido numa escola estadual do interior do município de Santo Ângelo-RS com duas turmas: uma do nono ano do ensino fundamental e outra do terceiro ano de ensino médio, tendo 13 e 19 alunos respectivamente. As turmas foram escolhidas pela facilidade de acesso, considerando que uma das autoras atuava como professora titular, o que favoreceu o desenvolvimento da pesquisa.

As respectivas turmas também foram escolhidas por estarem estudando conteúdos envolvendo geometria. A pesquisa foi colocada em prática durante as aulas de Matemática, com quatro períodos semanais de quarenta e cinco minutos no ensino médio e cinco períodos no fundamental, com quatro semanas de duração. 
O estudo realizado teve caráter qualitativo e quantitativo, pois além de analisar a elaboração dos mapas conceituais, foram aplicados dois testes sobre os conteúdos de Geometria de cada turma (veja tabela 1): um antes e outro depois do uso da técnica de mapeamento conceitual. Os estudantes também responderam a um questionário que buscou verificar se a utilização dos mapas conceituais contribuiu ou não no processo de ensino e aprendizagem.

Embora abordando diferentes conteúdos, foi utilizada a mesma estrutura na sequência de atividades em ambas as turmas. Após o término dos conteúdos relativos a Geometria, os estudantes realizaram uma avaliação, por meio de prova escrita, envolvendo todo o conteúdo abordado. Após ocorreram "oficinas" sobre aprendizagem significativa e mapas conceituais e na sequência, os alunos elaboraram mapas conceituais e posterior a essa elaboração foi realizada uma nova avaliação, abordando os mesmos conteúdos da primeira avaliação, afim de verificar se houve ou não uma melhora na aprendizagem.

Apesar de ter um total de 32 alunos como participantes ativos da pesquisa, para análise e discussão dos resultados foram escolhidos 2 mapas conceituais: 1 do nono ano e 1 do terceiro ano, por apresentarem características distintas de construção.

Para as duas turmas participantes, inicialmente foi cumprido o plano de trabalho no que se refere aos conteúdos de geometria e logo após foi realizada uma avaliação. Os conteúdos estudados e posteriormente avaliados em cada turma se encontram descritos na tabela 1 abaixo. Todos os conteúdos foram abordados da forma "tradicional" em aulas expositivas e resolução de problemas.

Tabela 1 - Conteúdos de Geometria abordados nas turmas integrantes do estudo

\begin{tabular}{|c|c|c|}
\hline & Nono Ano - Ensino Fundamental & Terceiro Ano - Ensino Médio \\
\hline Conteúdos & $\begin{array}{l}\text {-Segmentos proporcionais; } \\
\text {-Teorema de Tales; } \\
\text {-Figuras Semelhantes; } \\
\text {-Relações métricas no triângulo retângulo; } \\
\text {-Razões trigonométricas; } \\
\text {-Lei dos senos e lei dos cossenos. }\end{array}$ & $\begin{array}{l}\text {-Geometria espacial: prismas, para- } \\
\text { lelepípedo, cubo, pirâmides, cone, } \\
\text { cilindro e esfera. }\end{array}$ \\
\hline
\end{tabular}

Antes da aplicação da técnica de utilização do mapeamento conceitual, foi apresentado aos estudantes os principais conceitos relativos a Aprendizagem Significativa, bem como aspectos relativos ao mapeamento conceitual por meio de exemplos 
e suas diversas formas de utilização, cuja abordagem respeitou o nível de cada uma das turmas envolvidas no estudo.

Depois de se familiarizarem com a metodologia, propôs-se novamente a construção de mapas envolvendo conteúdos de geometria. Inicialmente a elaboração ocorreu utilizando cartazes e em seguida o software CmapTools foi apresentado.

Quando os estudantes começaram a elaborar os seus mapas relativos aos conteúdos de geometria estudados, inicialmente em grupos de três pessoas, foi incentivada a consulta de livros e internet. Logo foi possível observar que com o surgimento de novos conceitos e palavras ou frases de ligação, outros conceitos surgiam e consequentemente o mapa tomava forma ficando cada vez maior, antecipando assim a utilização do mesmo para facilitar o processo.

Depois da primeira elaboração dos mapas conceituais, alguns no papel e outros já fazendo uso do software, houve um momento de apresentação dos mesmos. Foi uma oportunidade importante para analisar se os estudantes entenderam como se constrói um mapa. Além disso, durante a apresentação, os alunos observavam que era possível ou necessário alterações em seus mapas conceituais. Essas vivências vão ao encontro das concepções de Moreira (2011), que acredita que o mapa conceitual é um bom instrumento para compartilhar, trocar e "negociar" significados.

Além da realização das avaliações e elaboração dos mapas, para contribuir no levantamento de dados da pesquisa, aplicou-se também um questionário contendo questões objetivas a fim de verificar se o trabalho com os mapas conceituais influenciou positivamente na aprendizagem e também analisar a satisfação dos alunos ao utilizar o software CmapTools.

\section{Mapa elaborado pelo nono ano do Ensino Fundamental}

Apresenta-se um dos mapas elaborados pelos estudantes, salientando que os mapas construídos, em sua maioria, sofreram modificações após a apresentação, tanto no que se refere às ligações entre conceitos e na maneira visual de como foram apresentados. As sugestões partiram de colegas e da professora, objetivando uma melhor visualização do conteúdo, porém sempre levando em consideração a satisfação e o entendimento de quem elaborou o mapa.

Cabe salientar que, de acordo com Tavares (2007), não existe um mapa certo ou mapa errado, considerando mapas onde os conceitos estão de acordo com o que 
é aceito pela comunidade cientifica sobre um determinado tema. Além disso a comparação dos mapas conceituais construídos em diferentes fases do trabalho sobre um tema pode indicar o progresso do aluno (PEÑA, 2005).

Ao observar o mapa da figura 1 , pode-se perceber que os conceitos se referem aos conteúdos de geometria do $9^{\circ}$ ano que é o conceito inicial encontrado na parte superior esquerda. No momento da apresentação, a aluna percebeu que a palavra de ligação "definição" que parte do conceito principal estava errada, pois define a geometria do $9^{\circ}$ ano como o Teorema de Tales. Também pareceu confuso destacar com a mesma cor conceitos contendo o nome do conteúdo com outros retângulos onde aparecem fórmulas, além da cor utilizada ter prejudicado a nitidez do mapa. Neste mapa chama a atenção que a aluna explorou vários recursos que o software oferece e foram inseridas algumas figuras no lugar dos exemplos.

Figura 1 - Mapa 4, dos alunos do ensino fundamental inicial

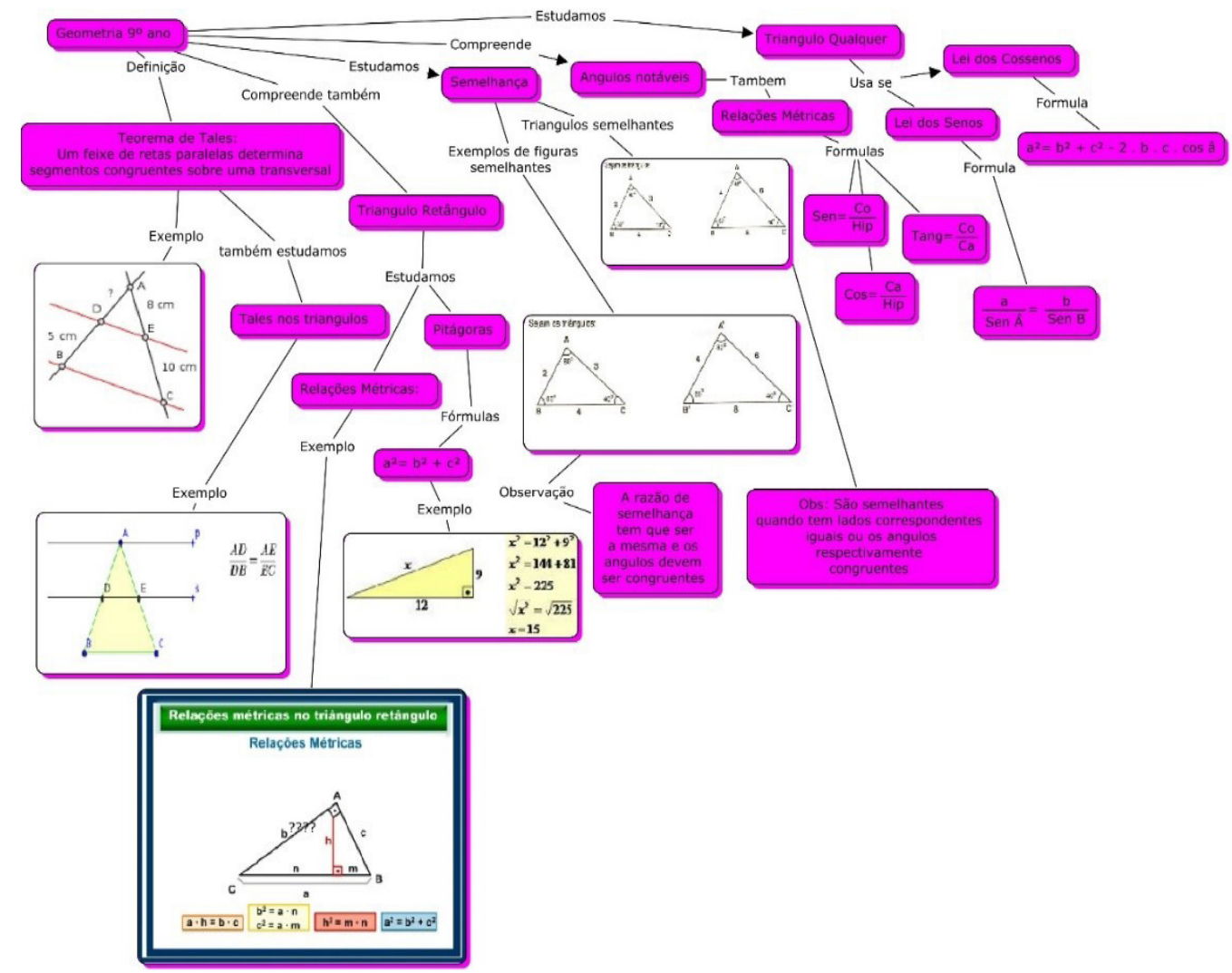

Fonte: Aluno 4, elaborado no CmapTools. 
Na figura 2, tem-se o mapa "corrigido" onde, além da correção de alguns erros referentes a palavras de ligação e conceitos, também foi sugerido que houvesse uma adequação das cores a fim de tornar mais clara a leitura do mapa, inclusive para quem o construiu. A linha pontilhada no mapa evidencia a ocorrência de reconciliação integradora.

Figura 2 - Mapa 4, dos alunos do ensino fundamental revisado

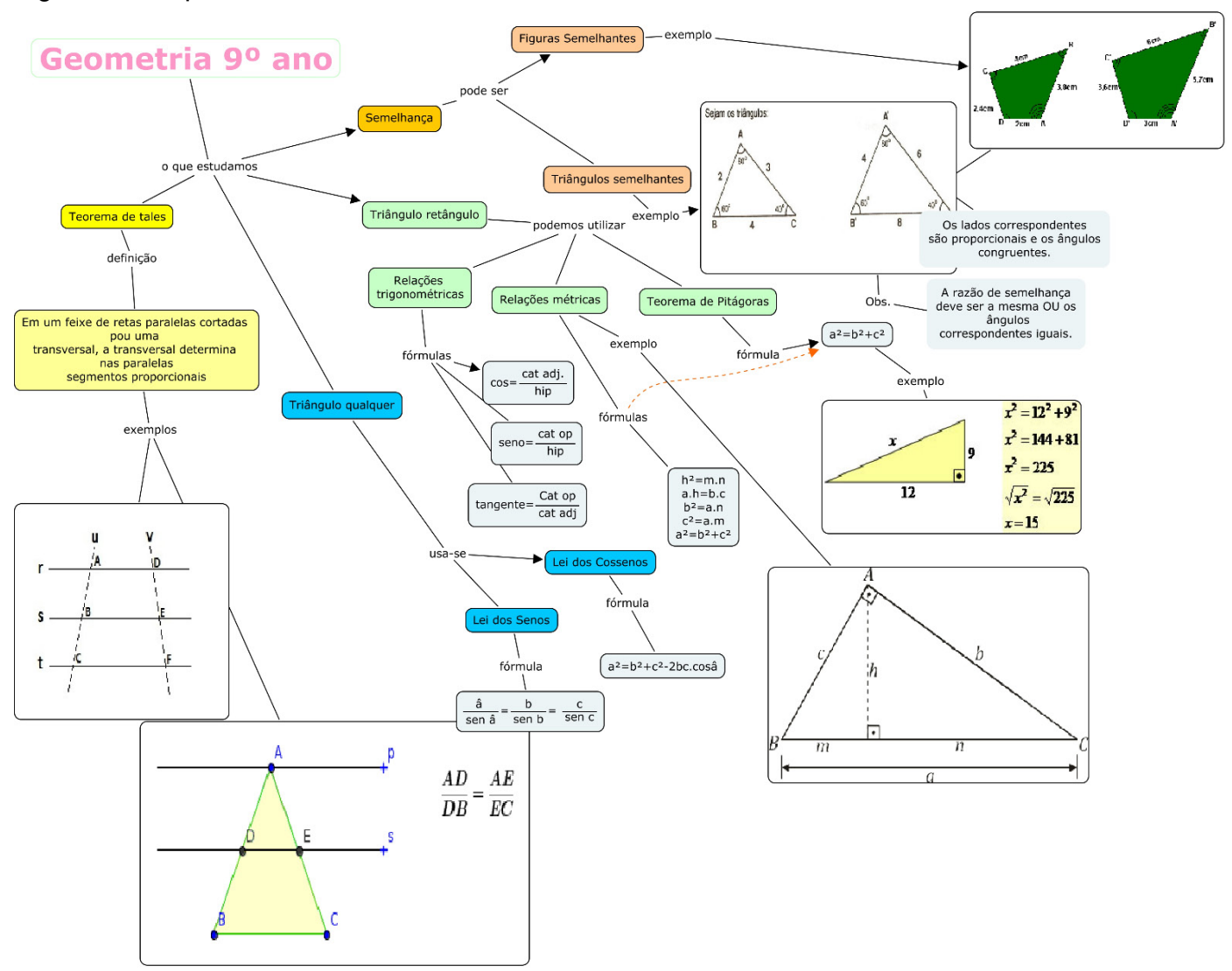

Fonte: Aluno 4, elaborado no CmapTools.

\section{Mapa elaborado pelo aluno do terceiro ano do ensino médio}

Após a oficina sobre mapas conceituais e teoria da aprendizagem significativa, os estudantes construíram os mapas conceituais em grupos, fazendo uso de cartolina e canetões, seguida de apresentação para a turma. Durante a apresentação os estudantes explicaram os seus mapas e, em alguns momentos surgiram sugestões 
de colegas e da professora. Além disso, na hora de apresentar, quem os construiu observou que alguns conceitos não estavam relacionados de maneira adequada ou que o mapa apresentava outros "equívocos", sobre isso Moreira (2011) lembra que ao analisar mapas elaborados por estudantes o professor deve levar em consideração que o mapa é do aluno e o importante não é se esse mapa está certo ou errado, mas sim se ele dá evidências de que o aluno está aprendendo significativamente o conteúdo.

A figura 3 apresenta um dos mapas construídos pelos alunos do terceiro ano. A visualização dos conteúdos não é muito nítida, mas a intenção da apresentação deste gráfico é dar a noção da construção de mapas conceituais pelo método tradicional de papel e lápis.

Figura 3 - Mapa conceitual dos alunos do ensino médio

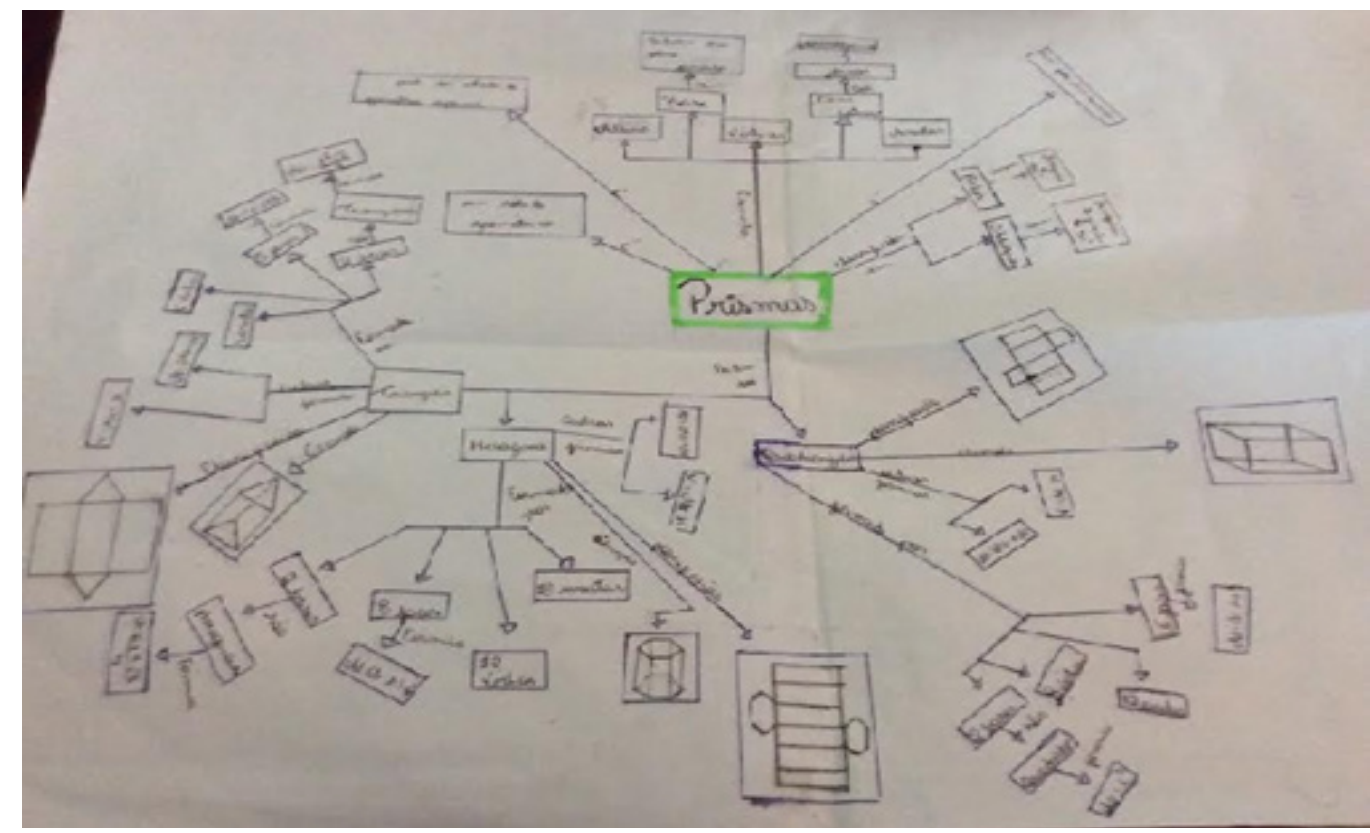

Fonte: Registro dos autores.

Após a apresentação dos mapas construídos pelos alunos utilizando papel e lápis, os alunos passaram a construir seus mapas conceituais utilizando-se do CmapTools, sendo que um dos mapas é apresentado na figura 4.

O mapa escolhido para a análise não foi elaborado abrangendo todo o conteúdo estudado. Foi escolhido para mostrar que, em um único mapa conceitual é possível relacionar inúmeros conceitos do conteúdo de todo o trimestre, mas também 
é possível destacar uma parte, que pode ser onde o estudante apresenta maiores dificuldades. No mapa da figura 4 , houve preocupação apenas com uma parte da geometria espacial: os prismas. A elaboração começou na parte superior e foram relacionados vários conceitos que envolvem os prismas.

Observa-se que os conceitos aparecem interligados corretamente e respeitam uma hierarquia, o que confirma a existência de diferenciação progressiva. Não foram inseridas figuras, porém uma característica interessante é que cores diferentes foram utilizadas facilitando a identificação dos principais tipos de prismas existentes: triangulares, quadrangulares e hexagonais. Além disso a cor amarela destacou os elementos do sólido estudado e a cor rosa está nas respectivas fórmulas. A característica mais evidente e que chama a atenção neste mapa são as linhas vermelhas que se cruzam e relacionam conceitos algumas vezes distantes, sendo assim a comprovação da ocorrência de reconciliação integradora, que é mais complexa, exigindo maior compreensão dos conceitos e suas relações, por este motivo observada com menos frequência em outros mapas.

Figura 4 - Mapa 5, ensino médio

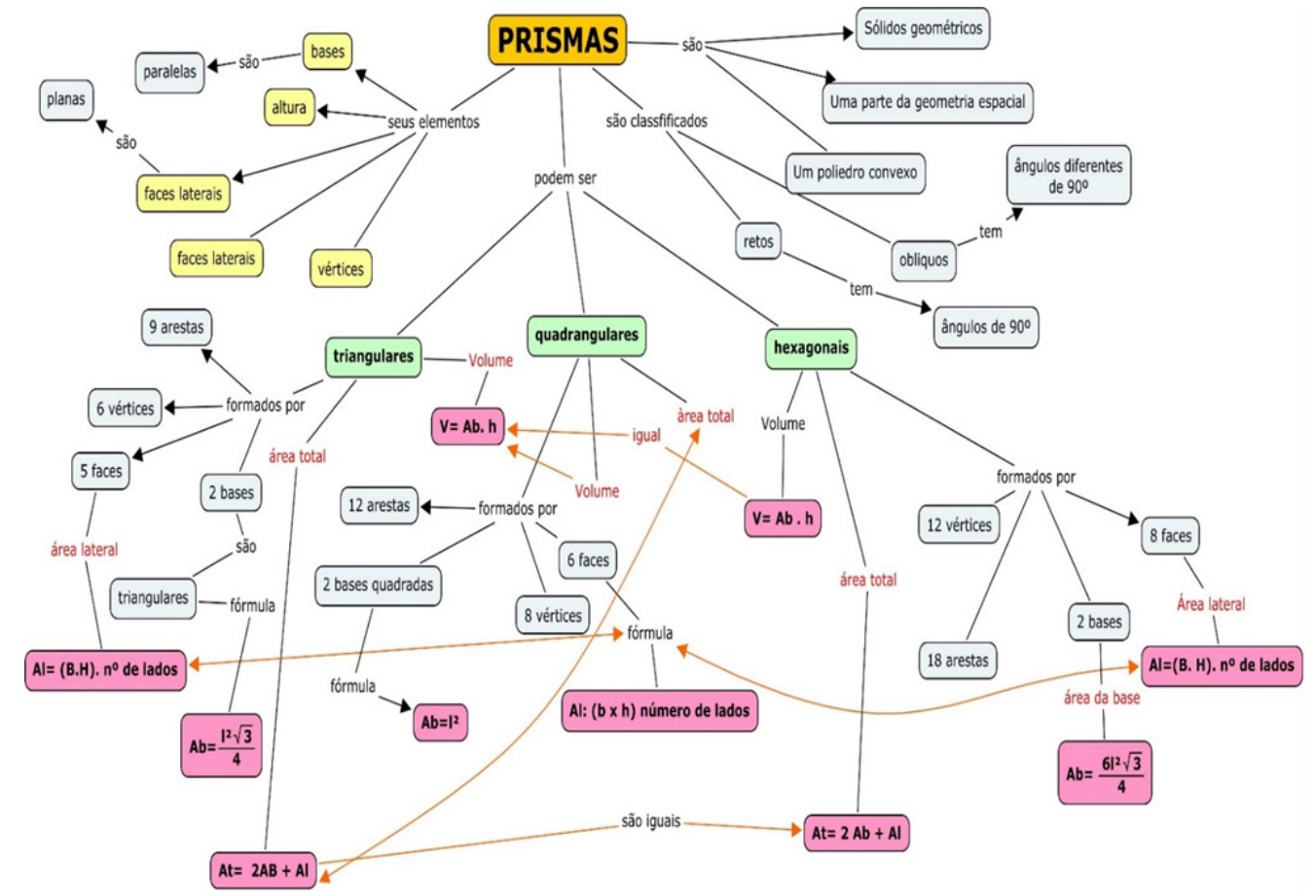

Fonte: Aluno 5, elaborado no CmapTools. 
De um modo geral, a análise dos mapas demonstra que os estudantes entenderam como se elabora um mapa conceitual, pois em todos os mapas, tanto do ensino fundamental quanto do ensino médio, foram identificadas as hierarquias entre os conceitos, denominada diferenciação progressiva que é um importante indício de aprendizagem significativa. Certamente puderam ser percebidas algumas dificuldades durante todo o processo de construção dos mapas, sendo que a principal delas foi a conexão entre os conceitos e isso deve-se a um estilo de aprendizagem em que o estudante apenas recebe informações e as decora para a avaliação, o que caracteriza uma aprendizagem mecânica. Contudo, somente o uso constante desta metodologia possibilitará o desenvolvimento das habilidades necessárias, visando uma aprendizagem significativa. Concordando com isto, Moreira (2011) explica que apesar da Teoria da Aprendizagem Significativa existir há muito tempo, ainda não houve uma apropriação da teoria, pois a escola continua fomentando a aprendizagem mecânica.

Os mapas também revelaram poucas relações cruzadas ${ }^{7}$, demonstrando a dificuldade dos estudantes em representar a reconciliação integradora, considera-se que somente um tempo maior de trabalho facilitaria este tipo de relações. Durante as aulas, constatou-se o envolvimento dos alunos com a nova metodologia, inclusive na parte inicial, onde foi apresentada a fundamentação teórica do estudo.

Para auxiliar na construção dos mapas, buscavam em livros e no caderno conceitos que poderiam ser inseridos. Constantemente procuravam esclarecer as dúvidas com a professora, o que demonstrou preocupação com a aprendizagem, diferente da forma passiva com que se comportam em uma aula expositiva. Contudo, pode-se afirmar que o uso de mapas conceituais proporcionou indícios de Aprendizagem Significativa, principalmente pelo surgimento nos mapas conceituais da reconciliação integradora e de relações cruzadas. Outros aspectos a este respeito são abordados na próxima seção.

\section{Análise dos dados do questionário}

Para uma análise mais aprofundada acerca do estudo realizado aplicou-se um questionário para as duas turmas participantes da pesquisa, após a realização das duas avaliações seguida do trabalho com os mapas conceituais e o software CmapTools. 
Foram elaboradas perguntas fechadas de múltipla escolha onde o aluno poderia assinalar uma alternativa. A seguir são apresentadas respostas às perguntas da turma do terceiro ano do ensino médio, composta por 19 alunos e para a turma do nono ano de ensino fundamental, composta por 13 alunos. Salienta-se que o questionário também abordava algumas questões relativas especificamente ao processo de instalação e utilização do software CmapTools, que se considerou não relevante para o presente relato.

Quando perguntados se os mapas conceituais contribuíram ou não na aprendizagem dos conteúdos estudados, os 19 alunos do $3^{\circ}$ ano entrevistados responderam que sim, reforçando a importância do trabalho com o mapeamento conceitual. Dos 13 alunos do nono ano que faziam parte da turma, todos responderam à primeira pergunta revelando que o trabalho com os mapas conceituais contribuiu positivamente na sua aprendizagem.

Outra pergunta foi em relação ao modo de elaborar os mapas conceituais. Esta referiu-se à construção com lápis e papel ou com a utilização do software CmapTools. No ensino médio, foi constatado que 16 alunos responderam preferir elaborar os mapas utilizando o software enquanto que 3 optaram pela construção com lápis e papel. Diante disso, acredita-se que os alunos que preferem não utilizar o software ainda não estão familiarizados com a tecnologia, pois não tem acesso a computadores em suas residências. No ensino fundamental, apenas um aluno demonstrou preferência por lápis e papel, opinião contrária dos outros 12 alunos que disseram preferir o software CmapTools.

Quando perguntados: A que você atribui o resultado da segunda avaliação? Doze (12) alunos do ensino médio que conseguiram melhorar a nota responderam que a elaboração dos mapas conceituais auxiliou para ampliar a compreensão do conteúdo. Os outros 7 alunos disseram não ter estudado para a segunda avaliação. Ressalta-se que dois estudantes, apesar de não terem estudado, mantiveram as notas da primeira avaliação. No ensino fundamental, todos os estudantes disseram que a elaboração dos mapas conceituais auxiliou para que compreendessem melhor o assunto estudado, inclusive os alunos que obtiveram as mesmas notas nas duas avaliações.

A última pergunta buscou averiguar se haveria a possibilidade de construir mapas conceituais em conteúdos de outras disciplinas além da Matemática e as respostas no ensino médio foram as seguintes: 8 concluíram que seria possível utilizar 
algumas vezes e 11 afirmaram que sim, que fariam uso do mapeamento conceitual em outras disciplinas. No ensino fundamental, dos 13 alunos que responderam às questões, 12 disseram que sim, utilizariam a metodologia em outras situações de aprendizagem e 1 aluno respondeu que poderia utilizar algumas vezes. Apesar dos estudantes não terem muito conhecimento sobre a metodologia dos mapas conceituais e do software CmapTools, de um modo geral, pode-se afirmar, diante das respostas analisadas, que os estudantes aprovaram a utilização do software na elaboração dos mapas e também houve um reconhecimento quanto a sua relevância no processo de ensino e aprendizagem, atuando como um importante organizador do conhecimento.

Com relação ao resultado das avaliações, para o nono ano, os resultados revelaram que a maioria dos alunos, um total de 9, conseguiram um resultado melhor na segunda avaliação e 3 alunos alcançaram a mesma nota em ambas. Um aluno teve um resultado pior mas deve-se considerar, neste caso, que a nota da primeira avaliação peso 5,0 foi 4,5 contra 4,4 da segunda.

Para o terceiro ano do ensino médio, constatou-se que 12 estudantes obtiveram uma melhora na segunda nota, para cinco alunos o resultado na segunda avaliação foi menor e 2 obtiveram notas iguais nas duas avaliações.

\section{Considerações finais}

Neste trabalho, procurou-se apresentar os mapas conceituais como uma estratégia facilitadora e auxiliar do processo de ensino e aprendizagem, como uma ferramenta capaz de auxiliar professores e alunos, visando a aprendizagem significativa, além de mostrar como podem ser elaborados. O trabalho com o mapeamento conceitual, muda a forma como tradicionalmente é encarada a aprendizagem, fazendo com que o estudante passe a ser o agente principal e ativo durante o processo. Sendo assim, acredita-se que os mapas conceituais passam a ser um importante aliado da aprendizagem, podendo ser utilizados em qualquer área do conhecimento e em diferentes momentos de aprendizagem.

Durante a realização deste estudo destacou-se a importância do ensino de Geometria no âmbito da disciplina de Matemática e buscou-se com a metodologia dos mapas conceituais, fundamentada na Teoria da Aprendizagem Significativa, instigar o interesse dos estudantes do decorrer das aulas e, principalmente oferecer condi- 
ções favoráveis para a aprendizagem. Vale salientar que a técnica do mapeamento conceitual pode ser estendida a outros conteúdos e disciplinas, dado os resultados positivos apresentados neste trabalho. A realidade tecnológica em que a escola está inserida é um desafio constante para os docentes. Diante disso, a pesquisa analisou se a elaboração dos mapas conceituais utilizando o software CmapTools contribuiu positivamente com o processo de ensino e aprendizagem de Matemática e pode-se observar enfaticamente a motivação dos estudantes durante as aulas.

Após a aplicação do estudo e análise dos resultados, pode-se afirmar que os mapas conceituais são um importante recurso e pode ser utilizado em diferentes momentos, pois colocam o estudante no centro da aprendizagem, fazendo com que durante o processo de elaboração de um mapa conceitual ele consiga organizar e relacionar conceitos importantes de um determinado conteúdo, buscando na sua estrutura cognitiva os subsunçores necessários que servirão de alicerce para um novo conhecimento, deixando de buscar somente decorar fórmulas e conceitos levando a sua aprendizagem de mecânica para uma aprendizagem significativa.

Por meio da análise do questionário e de todo o processo de elaboração dos mapas, observou-se alguma evolução no desempenho dos estudantes referente aos conteúdos de geometria estudados. Além disso, o mais notável foi a melhora no interesse dos estudantes quando tinham que buscar e elaborar conceitos para posteriormente apresentar o mapa construído para os colegas. Outro fator positivo que pode ser relatado é a troca de conhecimentos entre os alunos e entre alunos e o professor, fazendo com que ficassem evidentes possíveis lacunas na aprendizagem que, em uma aula tradicional não seriam facilmente observadas.

Utilizar os mapas conceituais propicia novas experiências educativas que incentivam a reflexão, a busca e a compreensão entre conceitos e neste processo, o erro, serve como um importante indicador para orientar professores e alunos visando superar dificuldades em determinados momentos da aprendizagem.

Na busca pela qualidade de ensino e priorizando o processo de ensino e aprendizagem, pesquisas e reflexões devem ser realizadas no intuito de procurar novas metodologias ou aperfeiçoar as já existentes. Investigar recursos adequados facilita a prática pedagógica e pode resultar em uma aprendizagem efetiva e prazerosa. 


\section{Using Concept Maps for Significant Learning of Geometry}

\section{Abstract}

The current educational context requires constant reflection on the methodologies used in the classroom. The search for alternatives capable of motivating students, facilitating learning and making them active subjects in the search for knowledge is essential. Therefore, this work presents the result of a research carried out with students from the ninth grade of elementary school and from the third grade of high school in a public school in the state of Rio Grande do Sul. The objective was to analyze whether the construction of Concept maps using CmapTools software can assist in the process of teaching and learning geometry. The observations took place during mathematics classes and the methodology used was based on the analysis of the maps prepared by the students. Results of a pre and post test with questions involving geometry content were also analyzed. It became evident that the elaboration of concept maps allows students and teachers to perceive the difficulties existing in the teaching and learning process. It can also be said that conceptual mapping combined with technology can be a strategy capable of offering positive perspectives for educational practice and enabling significant learning of geometry content. In addition, it motivated the participation of students in the dynamics of work in the classroom, during the construction and presentation of concept maps.

Keywords: Meaningful learning. Geometry. Concept maps. CmapTools software.

\section{Notas}

1 Para Ausubel (2003), estrutura cognitiva significado uma estrutura hierárquica de conceitos.

2 https://www.lucidchart.com/pages/pt

$3 \mathrm{https}: / /$ creately.com/pt/home/

4 https://gitmind.com/pt/

5 https://bubbl.us/

6 https://cmap.ihmc.us/cmaptools/

7 Relações cruzadas: interligações entres conteúdos que indicam a formação de proposições importantes relativas ao conteúdo estudado.

\section{Referências}

ABREU, N. A. Mapas Conceituais e suas aplicações. Artigo (Programa de Desenvolvimento Educacional (PDE) - Universidade Estadual do Norte do Paraná - UENP, Cornélio Procópio, Paraná, 2011. Disponível em: <http://www.diaadiaeducacao.pr.gov.br/portals/cadernospde/pdebusca/producoes_pde/2010/2010_uenp_mat_artigo_neuza_aparecida_de_abreu.pdf $>$. Acesso em: 06 outubro 2020 .

ALMEIDA, C., SCHEUNEMANN, C., LOPES, P. (2020). Formação continuada para professores em serviço do Ensino Fundamental Séries Iniciais: Aprendizagem Significativa e mapas conceituais. Revista Brasileira De Ensino De Ciências E Matemática, 2(2). https://doi.org/10.5335/ rbecm.v2i2.9957 
ALMOULOUD, S. A. et al. A geometria no ensino fundamental: reflexões sobre uma experiência de formação envolvendo professores e alunos. Revista brasileira de educação, nº 27, p. 94-108, 2004.

AUSUBEL, D.P. Aquisição e retenção de conhecimentos: Uma perspectiva cognitiva. Tradução de Teopisto, L. Revisão científica, Teodoro, V.D. 1.ed. Lisboa: Plátano. Janeiro, 2003.

BRASIL. Ministério da Educação. Secretaria da Educação Média e Tecnológica. Parâmetros curriculares nacionais: ensino médio: ciências da Natureza, Matemática e suas tecnologias. Brasília, DF: MEC: SEMTEC, 1998.

BRASIL. Ministério da Educação. Base Nacional Comum Curricular. MEC. Brasília, DF, 2018. Disponível em: <http://basenacionalcomum.mec.gov.br/images/BNCC_EI_EF_110518_versaofinal_site.pdf>. Acesso em: 26/10/2020.

CAÑAS et al. The Network Architecture of CmapTools. In: Web site of IHMC ( Institute for Human \& Machine Cognition), 2003. Disponível em: < https://cmap.ihmc.us/publications/whitepapers/ The \%20Network\%20Architecture\%20of\%20CmapTools.pdf>. Acesso em: 27 out. 2020.

KOBAYASHI, M. A construção da geometria pela criança. Bauru: EDUSC, 2001.

Lobato, L. F., ANDRADE, G. O. Desafios do Ensino de Geometria no Ensino Médio. Trabalho de Conclusão de Curso (Especialização em Ensino de Matemática) Instituto Federal de Educação, Ciência e Tecnologia do Piauí, Campus Corrente, 2019.

LORENZATO, S. Por que não ensinar geometria? Educação Matemática em Revista - SBEM, n. 4, p. 4-13, 1995.

MOREIRA, M. A. Aprendizagem significativa: A teoria e textos complementares. São Paulo: Livraria da Física, 2011.

Mapas Conceituais e Aprendizagem Significativa. 2012a. Disponível em: <http://www. if.ufrgs.br/ moreira/mapasport.pdf>. Acesso em: 02/10/2020.

M. A. Aprendizagem significativa em mapas conceituais. Porto Alegre: UFRGS, Instituto de Física, 2013.

NEVES, R. S. P. Aprender e ensinar Geometria: um desafio permanente. In: Programa Gestão da Aprendizagem Escolar - Gestar II. Matemática: Caderno de Teoria e Prática 3 - TP3: Matemática nas formas geométricas e na ecologia. Brasília: Ministério da Educação, Secretaria de Educação Básica, 2008. Disponível em: <http://portal.mec.gov.br/seb/arquivos/pdf/2008/gestar2/matematica/ tp3_matematica.pdf>. Acesso em: 10/11/2020.

NOVAK, J. D.; CAÑAS, A. J. A Teoria Subjacente aos Mapas Conceituais e como elaborá-los e usá-los. 2010. Disponível em: <http://www.revistas2.uepg.br/index.php/praxiseducativa/article/ view/1298>. Acesso em: 01/11/2020.

NUNES, C. B. O Processo Ensino-Aprendizagem-Avaliação de Geometria através da Resolução de Problemas: perspectivas didático-Matemáticas na formação inicial de professores de Matemática. 2010. Tese (Doutorado em Educação Matemática)- Universidade Estadual Paulista - UNESP, Rio Claro, 2010. Disponível em: <http://repositorio.unesp.br/bitstream/handle/11449/102122/ nunes_cb_dr_rcla.pdf?sequence=1>. Acesso em: 28/10/2020.

OLGIN, C. DE A.; GROENWALD, C. L. O. (2020). Temas contemporâneos integrados ao currículo de Matemática do Ensino Médio: projeto com o tema Arte. Ensino Em Re-Vista, 27(3), 909-933. https://doi.org/10.14393/ER-v27n3a2020-6 
PAVANELLO, R. M. O Abandono da geometria: uma visão histórica. 1989. Dissertação (Mestrado). Faculdade de Educação, Universidade Estadual de Campinas, Campinas, 1989.

PAVANELLO, R. M. O abandono do ensino de geometria no Brasil: causas e consequências. Zetetiké, n. 7, n. 1, Ano I. 1993.

PEÑA, A. O. Mapas Conceituais: uma técnica para aprender.São Paulo; Edições Loyla, 2005.

SANTOS, J. C. F. Aprendizagem significativa. 5. ed. Porto Alegre: Mediação, 2013.

SERAFIM, M. L.; SOUSA, R. P. Multimídia na Educação. 2011. Disponível em: <http://books. scielo.org/id/6pdyn/pdf/sousa-9788578791247-02.pdf> Acesso em 10/03/2020.

TAVARES, R. Construindo Mapas Conceituais. Ciências \& Cognição, v. 12, p. 72-85, 2007. Disponível em: <http://www.cienciasecognicao.org/pdf/v12/m347187.pdf>. Acesso em: 01/11/2020.

VALENTE, V. R. Uma história da matemática escolar no Brasil (1730-1930). São Paulo: Annablume/FAPESP, 1999.

VITRAC, B. A invenção da geometria. São Paulo: Ediouro, 2006. 